\title{
Atividades antinociceptiva e antiinflamatória do extrato etanólico de Luehea divaricata
}

BATISTA, E.K.F. ${ }^{*}$; TRINDADE, H.I. ${ }^{\prime}$; LIRA, S.R.S. ${ }^{2}$; MULLER, J.B.B.S. ${ }^{3}$; SILVA, L.L.B. ${ }^{3}$; BATISTA, M.C.S. ${ }^{1}$ - Universidade Federal do Piauí (UFPI) - Programa de Pós-Graduação em Ciência Animal - Campus Universitário Min. Petronio Portella, Av. Universitária s/n CEP: 64049-550 - Teresina, PI, Fone-Fax: (86) 3215-5753. ${ }^{2}$ Universidade Federal do Piauí (UFPI) Departamento de Morfofisiologia Veterinária - UFPI - Campus Universitário Min. Petronio Portella, Av. Universitária s/n CEP: 64049-550 - Teresina, Pl. ${ }^{3}$ Universidade Federal do Piauí (UFPI) - Programa de Pós-Graduação em Farmacologia - Campus Universitário Min. Petronio Portella, Av. Universitária s/nº CEP: 64049-550 - Teresina, PI. *Autor para correspondência: emanuellefrota@yahoo.com.br

RESUMO: Considerando os diferentes usos etnofarmacológicos apresentados pela planta Luehea divaricata, realizou-se este estudo com o objetivo de avaliar as atividades antinociceptiva e antinflamatória do extrato etanólico de suas folhas, em modelo animal, nas dosagens de 20, 40, 80 e $160 \mathrm{mg} / \mathrm{Kg}$, por via oral. Foram realizados os seguintes testes: contorções abdominais induzidas pelo acido acético, placa quente, formalina e edema de pata induzido por carragenina. Foram utilizados camundongos Swiss (20-25 g) para os três primeiros testes e ratos Wistar (180-250 g), para o último, divididos em seis grupos de oito animais, totalizando 48 animais em cada parâmetro de avaliação. Os resultados foram analisados estatisticamente pela análise de variância a $5 \%$ de probabilidade, para verificar quais os tratamentos que diferiram entre si, e estes foram submetidos aos testes de Kruskall-Wallis e Student-Newman-Keuls. O extrato etanólico das folhas de L. divaricata (EEtOH-Ld), nas diferentes doses estudadas, apresentou significativa atividade antinociceptiva sobre a dor induzida quimicamente por injeções intraperitoneal de acido acético e intraplantar de formalina. Na dosagem de $160 \mathrm{mg} / \mathrm{Kg}$, esse extrato apresentou ação analgésica central, aos 120 minutos de observação, no teste de placa quente e reduziu o edema de pata induzido pela administração de carragenina, uma hora após a administração do agente inflamatório, semelhante ao efeito produzido pelo fármaco padrão.

Palavras-chave: açoita-cavalo, dor, plantas medicinais.

\begin{abstract}
Antinociceptive and anti-inflammatory activities of Luehea divaricate ethanol extract. Considering the different ethnopharmacological uses submitted by the plant Luehea divaricata, this study took place in order to evaluate the antinociceptive and anti-inflammatory activities of the ethanol extract of the leaves in an animal model, the dosages of $20,40,80$ and $160 \mathrm{mg} / \mathrm{kg}$ by oral intake. The following tests were performed: writhing induced by acetic acid, hot plate, formalin, and paw edema induced by carrageenan. Swiss mice (20-25 g) were used for the first three tests and Wistar rats $(180-250 \mathrm{~g})$ for the last, divided into six groups, each of eight animals, totaling 48 animals for each assessment parameter. The results were statistically analyzed by analysis of variance at $5 \%$ probability to verify which treatments differ, and these were tested by Kruskal-Wallis and Student-Newman-Keuls. The ethanol extract of $L$. divaricataleaves (EEtOH-Ld) at the different studied doses showed significant antinociceptive activity on chemically induced pain by intraperitoneal injections of acetic acid and intraplantar formalin. At a dosage of $160 \mathrm{mg} / \mathrm{kg}$, this extract showed a central analgesic action after 120 minutes of observation in the hot plate test and reduced action in the paw edema induced by carrageenan one hour after the administration of the inflammatory agent, similar to the effect produced by the standard drug.
\end{abstract}

Keywords:horse-whips, pain, medicinal plants.

Recebido para publicação em 15/07/2015 


\section{INTRODUÇÃO}

As plantas medicinais vêm sendo utilizadas popularmente desde os primórdios da civilização, com diversas finalidades, principalmente para cura e prevenção de doenças. Esse conhecimento, passado oralmente através das gerações, é uma importante fonte para a descoberta de novos princípios ativos (Santos et al., 2011). Estima-se atualmente que 25 a $30 \%$ de todas as drogas avaliadas como agentes terapêuticos são derivadas de produtos naturais (Newman \& Cragg, 2007).

O Brasil é reconhecido mundialmente como um dos maiores detentores da biodiversidade do planeta, possuindo mais de $20 \%$ de todas as espécies vegetais do mundo, com inúmeras apresentando potencial medicinal (Baggio \& Medrado, 2003; Dutra, 2009). Este alto padrão de biodiversidade dá ao Brasil uma extraordinária estratégia de pesquisa na área de princípios ativos (Guerra \& Nodari, 2010). A grande parte dos princípios ativos de importância farmacológica encontrada nos extratos vegetais, de modo geral, é oriunda de uma variedade de metabólitos secundários que possuem uma constituição complexa, alcançando alvos terapêuticos nas doenças humanas e que são produzidos para modular seus próprios metabolismos (Ferreira \& Pinto, 2010).

Entre as espécies vegetais presentes no território nacional, ressalta-se a $L$. divaricata, conhecida popularmente por açoita-cavalo, ibatingui, ivatingui, pau-de-canga e caiboti. Pertence a família Tiliaceae e está incluída na ordem Malvales. Ocorre no Piauí, Sul da Bahia, Rio de Janeiro, São Paulo, Minas Gerais, Goiás e Mato Grosso do Sul até o Rio Grande do Sul, e também na Argentina, Uruguai e Paraguai (Lorenzi, 1992; Alice et al., 1995).

Esta planta possui diversos usos etnofarmacêuticos, na forma de infusão de folhas e decoto das cascas, como antiinflamatório, antianêmico, diurético, antisséptico bucal, entre outros. A raiz é considerada um depurativo e antiinflamatório. As cascas são utilizadas como antidiarreico, adstringente, antipirético, antitumoral e antianêmico. As folhas, cascas e flores são indicadas na cicatrização de feridas, lavagem vaginal, diurético, antiartrítico, antileucorreico, tônico e em afecções do aparelho respiratório. As folhas são indicadas contra disenteria, reumatismo, blenorragia e tumores, objetivando os efeitos antiinflamatório, calmante e antiespasmódico (Tanaka et al., 2005; Muller, 2006).

As folhas da $L$. divaricata, oriunda de outros Estados, mostraram a presença de flavonoides, saponinas, taninos caquéticos, mucilagem, e em menor quantidade, alcaloides, óleos fixos, antocianinas, carotenoides, e polissacarídeos, em analise fitoquímica (Bortoluzzi et al., 2002).
No entanto, apesar das indicações do uso popular desta planta em processos inflamatórios, a literatura relata poucos estudos com o extrato etanólico de suas folhas. Portanto, este estudo teve como objetivo avaliar as atividades antinociceptiva e antiinflamatória do extrato etanólico das folhas de Luehea divaricata, em modelo animal.

\section{MATERIAL E MÉTODOS}

Os experimentos foram realizados no Laboratório de Ciências Fisiológicas do Departamento de Morfofisiologia Veterinária no Centro de Ciências Agrárias (CCA) da Universidade Federal do Piauí (UFPI).

Para a preparação do extrato, foram coletadas as folhas da planta L. divaricata (açoitacavalo) no Povoado Alegria, na zona rural de Teresina. A exsicata foi identificada no Herbário Graziela Barroso, da UFPI, sob o registro TEPB 30.119. O material foi desidratado em estufa ( \pm $45^{\circ} \mathrm{C}$ ) por uma semana, triturado em moinho de facas e submetido à extração com etanol por 12 dias a temperatura ambiente e ao abrigo da luz, sendo posteriormente filtrada em papel de filtro e a solução obtida concentrada em evaporador rotatório a $40^{\circ} \mathrm{C}$ e depois submetido à liofilização.

Utilizaram-se camundongos Swiss (20-25 g) para os testes de contorções abdominais, placa quente e da formalina, e ratos Wistar (180-250 g) para o teste de edema de pata. Todos os animais foram provenientes do Biotério do CCA da UFPI e foram mantidos em gaiolas, à temperatura ambiente $\left(25 \pm 3^{\circ} \mathrm{C}\right)$, em ciclo claro-escuro de 12 horas, com comida e água à vontade. Oito horas antes do início dos experimentos, foram mantidos em jejum sólido. O protocolo experimental foi submetido e aprovado pelo Comitê de Ética em Experimentação Animal da UFPI, com parecer $n^{\circ} 32 / 12$. Ao final de cada protocolo experimental, os animais foram eutanasiados por sobredose anestésica (cetamina$50 \mathrm{mg} / \mathrm{kg}$ e xilazina- $3 \mathrm{mg} / \mathrm{kg}$ ) intraperitoneal, seguindo a recomendação da resolução $n^{\circ} 714$ de 20/06/2002 do Conselho Federal de Medicina Veterinária CFMV.

Os modelos animais utilizados para avaliação da atividade antinociceptiva de um extrato os substância isolada envolvem diversas respostas nociceptivas geradas por estímulos químicos ou térmicos (Silva et al., 2013). Para a avaliação da atividade antinociceptiva através do teste de contorções abdominais induzidas por ácido acético, foram utilizados 48 camundongos divididos em seis grupos de oito, os quais foram pré-tratados com o EEtOH-Ld nas dosagens de 20, 40, 80 e $160 \mathrm{mg} / \mathrm{kg}$, por via oral $(10 \mathrm{~mL} / \mathrm{kg})$ uma hora antes da injeção de

Rev. Bras. PI. Med., Campinas, v.18, n.2, p.433-441, 2016. 
solução de ácido acético. O grupo controle negativo recebeu o mesmo volume do veículo utilizado para diluir o extrato (água destilada, $10 \mathrm{~mL} / \mathrm{kg}$ ), e o controle positivo recebeu indometacina $(10 \mathrm{mg} / \mathrm{kg}$, via oral). A indometacina é um anti-inflamatório não esteroidal, que possui potente atividade analgésica e anti-inflamatória, inibindo a transmissão nociceptiva, além da prevenção do edema e da inflamação (Steagall et al., 2009).

A resposta nociceptiva foi induzida pela injeção intraperitoneal (i.p.) de ácido acético $0,8 \%(0,1 \mathrm{~mL} / 10 \mathrm{~g})$ diluído em solução salina $(0,9 \%)$. Após a administração do ácido acético os camundongos foram colocados em uma caixa de acrílico e observados para a contagem do número de contorções abdominais, durante 20 minutos. O total de contorções desse período corresponde ao índice da resposta nociceptiva (Queiroz et al., 2010). As contorções abdominais consistem na contração da musculatura abdominal seguidas de torção do tronco e extensão de uma ou ambas as patas posteriores, produzidas em resposta a irritação peritoneal e peritonite produzidas por ácidos fracos ou agentes inflamatórios (Oliveira et al., 2005). A atividade antinociceptiva foi determinada com base na inibição das contorções abdominais nos animais pré-tratados com o extrato.

No teste da formalina foram utilizados 48 camundongos divididos em seis grupos de oito animais, os quais receberam por via oral o EEtOHLd (20, 40, 80 e $160 \mathrm{mg} / \mathrm{kg})$ e o controle negativo (veiculo, $10 \mathrm{~mL} / \mathrm{kg}$ ), e por via intraperitoneal, o controle positivo (morfina, $7,5 \mathrm{mg} / \mathrm{kg}$ ). Uma hora depois foi administrado $20 \mu \mathrm{L}$ de uma solução de formalina $2,5 \%$ intraplantarmente no membro pélvico direito (pata traseira). Foi cronometrado o tempo que o animal lambe, sacode ou morde a pata injetada com formalina, no período de 0-5 minutos e de 15-30 minutos após a sua aplicação. Esse modelo mostra duas fases de sensibilidade dolorosa. A primeira, de 0-5 minutos após a injeção de formalina, é chamada de fase neurogênica, na qual ocorre ativação direta dos nociceptores locais pela formalina (Hunskaar \& Hole, 1987). A segunda fase (dor inflamatória) representa um tipo de dor inflamatória e envolve transmissão sináptica reforçada pela medula espinhal, bem como pela liberação dos mediadores inflamatórios locais, como prostaglandinas, serotonina, histamina e bradicinina (Padilha et al., 2009).

A porcentagem de inibição do tempo que o animal lambe, sacode ou morde a pata injetada com formalina foi calculada de acordo com a formula: \%inibição $=(100-T t / T c) \times 100$, onde $\mathrm{Tt}$ representa a média do tempo que o animal passa lambendo, sacodindo ou mordendo a pata com formalina no grupo tratado e Tc representa essa média no grupo controle.

Outro ensaio utilizado para medir o efeito analgésico do EEtoH-Ld, foi teste da placa quente. Esse teste avalia o tempo que os animais permanecem sobre uma placa metálica aquecida até reagirem ao estímulo térmico e é bastante utilizado como um modelo específico para a detecção de substâncias analgésicas de efeito central

(Silva et al., 2013). Foram utilizados 48 camundongos divididos em seis grupos, havendo oito animais em cada grupo. Cada camundongo foi colocado individualmente sobre a placa de metal previamente aquecida a $55 \pm 1^{\circ} \mathrm{C}$ utilizandose 0 aparelho de modelo de placa quente (EFF 361). Registrou-se o tempo necessário para que os animais apresentassem o reflexo de lamber, morder ou levantar as patas sobre a placa (tempo de latência para a resposta nociceptiva). As aferições foram realizadas a cada 30 minutos, iniciando no momento da administração do extrato (Tempo 0) e terminando 120 minutos após administração do EEtoH-Ld, nas dosagens de 20, 40, 80 e 160 mg/ $\mathrm{kg}$ por via oral $(10 \mathrm{~mL} / \mathrm{kg})$ e dos controles positivo (morfina, 7,5 mg/Kg, intraperitoneal) e negativo (10 $\mathrm{mL} / \mathrm{kg}$, via oral). O tempo de reação do animal foi registrado com um cronômetro e o tempo máximo de permanência do animal sobre a placa foi de 30 segundos, para evitar danos teciduais nas patas (D’Amour \& Smith, 1941).

O ultimo teste realizado foi o edema de pata induzido por carragenina em ratos. Esse teste envolveu dois grupos controles e quatro grupos experimentais, havendo oito ratos em cada grupo. Antes da administração dos tratamentos (tempo Oh), o volume da pata traseira direita de todos os animais foi mensurado por plestismometria e a pata marcada em altura definida, garantindo a regularidade da medida.

Os animais foram tratados com EEtOHLd (20, 40, 80 e $160 \mathrm{mg} / \mathrm{kg}$, vo), indometacina (10 mg/kg, vo) como controle positivo e o grupo controle negativo tratado somente com o veiculo $(10 \mathrm{~mL} / \mathrm{kg}$, vo). Após uma hora da administração dos tratamentos, o edema foi induzido por injeção intraplantar de $100 \mu \mathrm{L}$ de carragenina a $1 \%$ no membro pélvico (pata traseira) direito dos ratos. A formação de edema foi quantificada por mudanças no volume desse membro. Aferiu-se este volume antes e após 30, 60, 120 e 180 minutos da administração da carragenina, pela imersão da pata injetada no pletismômetro, que deslocou o liquido contido no aparelho. O cálculo do edema da pata foi realizado através dos valores de variação entre o volume da pata $(\Delta, \mathrm{em} \mathrm{mL})$ antes da aplicação da carragenina e o seu volume após a injeção, após 30, 60, 120 e 180 minutos (Ferreira, 1979).

Os resultados obtidos por meio dos testes

Rev. Bras. PI. Med., Campinas, v.18, n.2, p.433-441, 2016. 
acima foram expressos como média \pm desvio padrão. Os dados foram analisados estatisticamente pela análise de variância a $5 \%$ de probabilidade (ANOVA) e quando foi identificada diferença estatística, foram aplicados os testes de KruskallWallis e Student-Newman-Keuls, também com 5\% de probabilidade.

\section{RESULTADOS E DISCUSSÃO}

No teste de contorções abdominais induzidas por ácido acético o extrato etanólico das folhas de $L$. divaricata, administrado por via oral, apresentou ação antinociceptiva significativa se comparada ao controle negativo, com inibição no numero de contorções de $46,34 \%, 45,99 \%, 54,73 \%$ e $62,57 \%$ nas dosagens de 20, 40, 80 e $160 \mathrm{mg} / \mathrm{Kg}$, respectivamente (Figura 1).

Verificou-se uma redução dessas contorções nos animais tratados com EEtOH-Ld na dosagem de $80 \mathrm{mg} / \mathrm{Kg}$, semelhante ao observado nos animais tratados com a indometacina, que é um reconhecido antiinflamatório não esteroidal. A atividade antinociceptiva desse extrato é comprovada pela redução do numero de contorções na posologia de $160 \mathrm{mg} / \mathrm{Kg}$, que foi mais efetiva que a indometacina. Rosa et al. (2014), avaliando a atividade antinociceptiva do extrato bruto de $L$. divaricata, observou que esse extrato foi eficaz na redução do comportamento de contorção abdominal na dose de $30 \mathrm{mg} / \mathrm{Kg}$. Portanto, pode-se inferir que os compostos químicos do EEtOH-Ld contribuam para o alívio de dores leves a moderadas.

O efeito algésico do ácido acético ocorre devido uma reação inflamatória aguda relacionada com liberação de mediadores presentes em processos inflamatórios como as prostaglandinas, leucotrienos, histamina, serotonina, bradicinina e eicosanoides (Verma et al., 2005; Bahamonde et al., 2013), resultando em aumento da síntese de ciclooxigenases (COOX), lipooxigenase (LOX) e prostaglandinas (Ikeda et al., 2001; Radu et al., 2013).

Além disso, a ação do ácido acético sobre macrófagos e basófilos, existentes na cavidade abdominal, induz liberação de citocinas, como IL-8, IL-1 $\beta$ e TNF- $\alpha$, que estimulam neurônios aferentes primários, aumentando a liberação de aspartato e glutamato no fluido cérebro-espinhal e, juntamente com os outros mediadores, pode induzir a reação nociceptiva característica observada nesse modelo (Feng et al., 2003). O ácido acético desencadeia ainda vasodilatação e permeabilidade vascular (Verri et al., 2006; Parveen et al., 2007).

Foi avaliado o efeito do extrato metanólico bruto das folhas de L. divaricata $(250,500$ e $1000 \mathrm{mg} / \mathrm{kg}$, vo) sobre às contorções abdominais induzidas pelo ácido acético $(0,8 \%)$ e verificou-se que o efeito daquele extrato foi significativo somente na dosagem de $1000 \mathrm{mg} / \mathrm{kg}$. O resultado deste estudo permite sugerir que EEtoH-Ld demostra ser mais potente, quando comparado ao extrato metanólico bruto das folhas de $L$. divaricata usado naquele experimento (Muller, 2006).

A administração oral do EEtOH-Ld, nas dosagens de 20, 40, 80 e $160 \mathrm{mg} / \mathrm{Kg}$, reduziu em $15,01 \%, 17,05 \%, 20,68 \%$ e $31,32 \%$, respectivamente, o comportamento do animal de lamber a pata injetada com formalina na primeira fase (dor neurogênica), assim como $12,73 \%, 22,62 \%, 34,01 \%$ e $56,20 \%$,

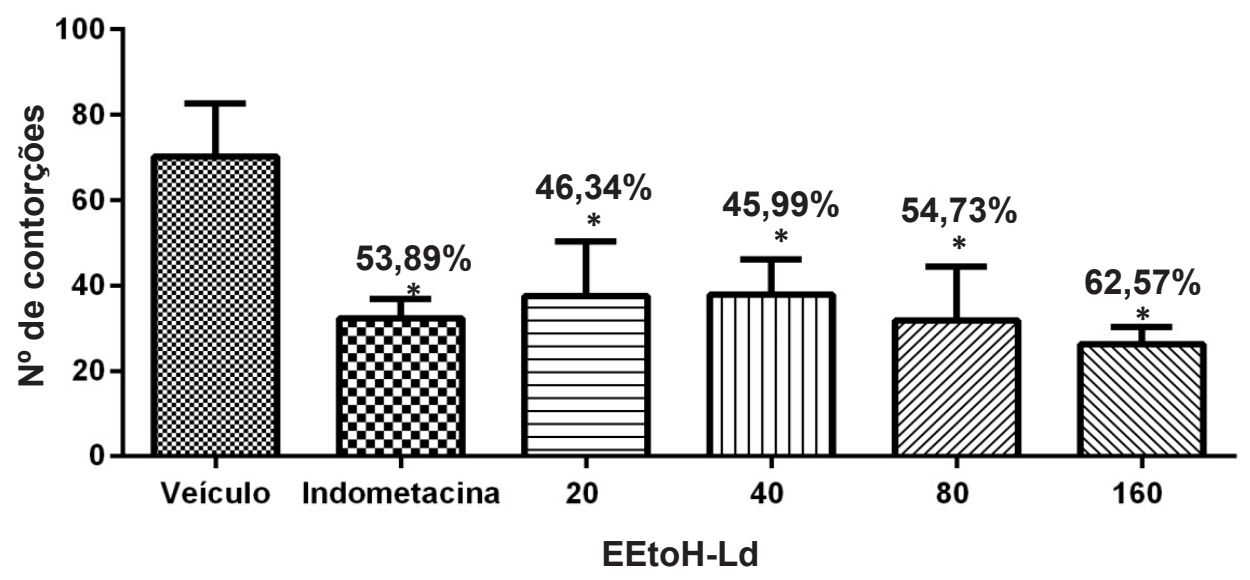

FIGURA 1. Efeito do extrato etanólico das folhas de Luehea divaricata (EEtoH-Ld) e da indometacina via oral sobre as contorções abdominais induzidas por ácido acético em camundongos $(n=8)$. Controle negativo (veículo), indometacina $(10 \mathrm{mg} / \mathrm{kg})$ e EEtoH-Ld $(20,40,80 \mathrm{e} 160 \mathrm{mg} / \mathrm{kg})$ foram administrados 60 minutos antes da injeção intraperitoneal de ácido acético $0,8 \%$ (v/v) e o número de contorções abdominais foi avaliado durante 20 minutos. Os valores em cada coluna representam a média \pm d.p.m. do número de contorções abdominais. Foi realizado o teste ANOVA, seguido pelo teste de Kruskall-Wallis. Valores significativos: $\mathrm{P}^{*}<0,05$ versus veículo. 
respectivamente, na segunda fase (dor inflamatória) do teste, em relação ao controle negativo. A morfina (7,5 mg/Kg; i.p.), um analgésico opióide, foi utilizada como fármacos padrão e reduziu significativamente o tempo de lambedura da pata nas duas fases desse teste (Figura 2).

O teste da formalina consiste na injeção intraplantar de solução de formaldeído (formalina) na pata posterior do animal, o qual induz dor intensa pela estimulação direta dos nociceptores, caracterizada por vigorosas lambidas, mordidas e batidas na pata injetada com o irritante (Hess, 2006). Esse teste, considerado de longa duração, permite a verificação de sinais presentes na fase de modulação dos impulsos nervosos, e também, observar a participação de sistemas endógenos como o dos opióides (Munguia, 2007).

Neste teste, podem ser caracterizadas duas fases de comportamento nociceptivo, que parecem envolver diferentes estímulos. A primeira fase (neurogênica) inicia-se imediatamente após a injeção de formalina, estendendo-se pelos primeiros cinco minutos e resulta da estimulação química direta dos nociceptores, principalmente das fibras C (Sulaiman et al., 2008), sendo associada à liberação de neuropeptídeos e outras substancias que produzem respostas locais, denominada de inflamação neurogênica (Mamet et al., 2003).

A liberação de mediadores nociceptivos nessa primeira fase causa extravasamento plasmático, vasodilatação de capilares vizinhos, ativação de fibras simpáticas, de mastócitos e macrófagos. Também induz a liberação de mediadores inflamatórios, como histamina, serotonina, bradicinina e prostaglandinas (Ferreira et al., 2004), que produzem sensibilização das vias periféricas e centrais de condução da dor, característica da segunda fase (fase inflamatória), observada de quinze a trinta minutos após a injeção de formalina (Tjolsen et al., 1992).

O extrato metanólico bruto das folhas de L. divaricata na dosagem de $1000 \mathrm{mg} / \mathrm{kg}$, VO,
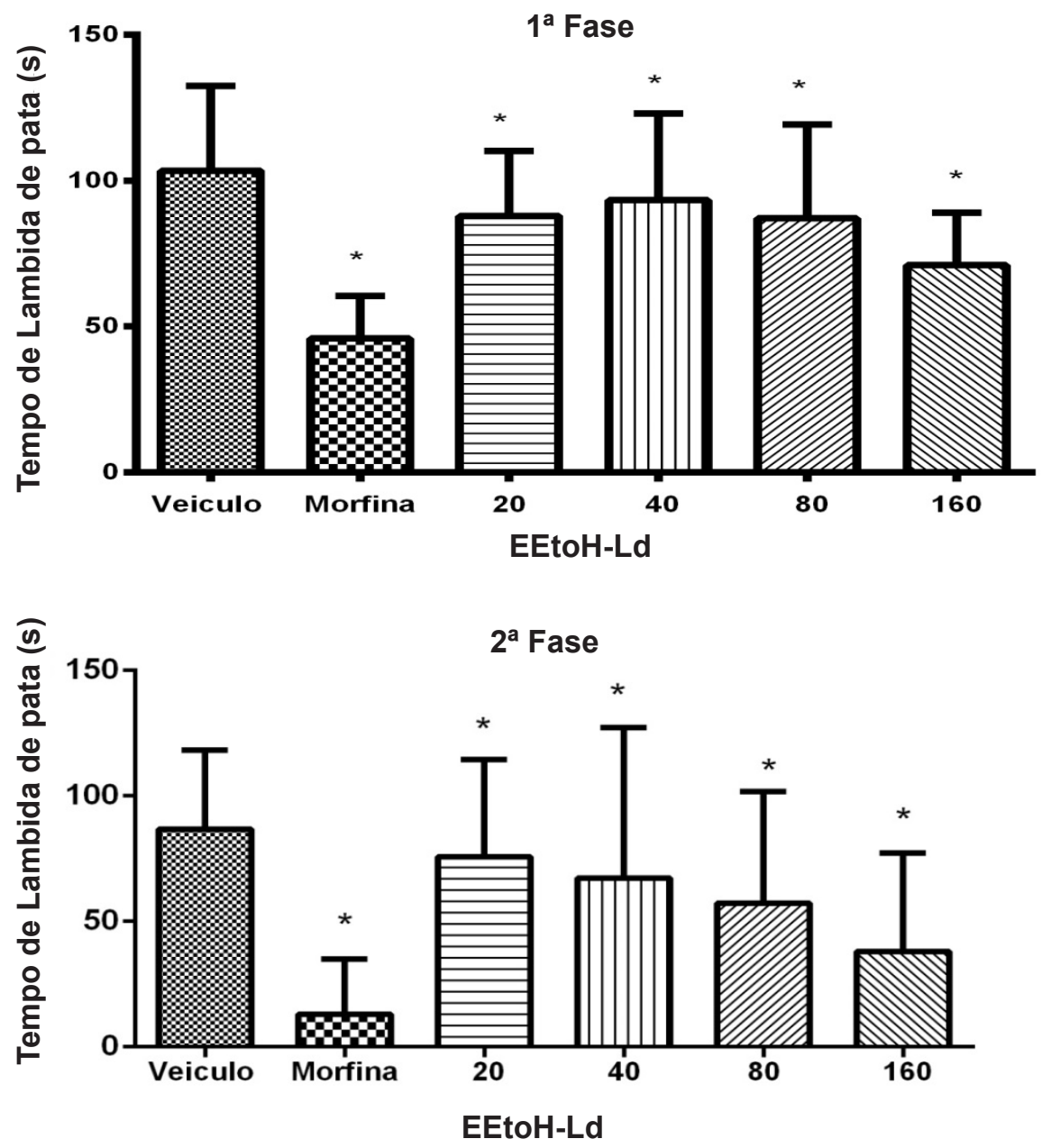

FIGURA 2. Efeito do extrato etanólico das folhas de Luehea divaricata (EEtoH-Ld) e da morfina no teste da formalina ( $1^{\mathrm{a}}$ e $2^{\mathrm{a}}$ fases) $(\mathrm{n}=8)$. Controle negativo (veículo), morfina $(7,5 \mathrm{mg} / \mathrm{kg}$, IP) e EEtoH-Ld $(20,40,80$ e160 $\mathrm{mg} / \mathrm{kg}$ ). Os valores em cada coluna representam a média \pm d.p.m. Foi realizado o teste ANOVA, seguido pelo teste de Kruskall-Wallis. Valores significativos: $\mathrm{P}^{*}<0,05$ versus veículo. 
apresenta atividade antinociceptiva pelo teste de formalina apenas na fase inflamatória. Porem, o EEtOH-Ld apresentou inibição da ação nociceptiva causada pela formalina em ambas as fases analisadas, diferindo significativamente do veiculo (Muller, 2006).

Ambas as fases desse teste podem ser suprimidas por fármacos de ação central, como a morfina (analgésico opióide), que diminui a resposta nociceptiva causada pela formalina. Na segunda fase há a participação de vários mediadores que podem estar envolvidos na dor inflamatória, que é bastante sensível à ação dos fármacos antiinflamatórios não esteroidais, bem como fármacos de ação periférica, como os esteroides (Tjolsen et al., 1992).

$\mathrm{Na}$ avaliação da reatividade ao estímulo térmico, verificou-se que nos tempos 30,60 e 90 minutos, os animais tratados com EEtOH-Ld nas dosagens de 20, 40, 80 e $160 \mathrm{mg} / \mathrm{Kg}$ apresentaram tempo de reação à placa quente semelhante ao grupo controle. No tempo de observação de 120 minutos, o extrato, na posologia de $160 \mathrm{mg} / \mathrm{Kg}$, não diferiu estatisticamente da morfina $(7,5 \mathrm{mg} / \mathrm{Kg}$, IP), usada como fármaco de referencia (Figura 3). Esse resultado sugere que o EEtOH-Ld possui atividade analgésica central semelhante a morfina, utilizada como fármaco padrão.

O teste da placa quente mostra uma resposta do animal a um estimulo térmico que é associado à neurotransmissão central, sendo muito sensível aos analgésicos que atuam em nível central. Nesse teste, um estímulo térmico ativa os nociceptores (fibras $C$ não mielinizadas) que transmitem a informação a regiões especificas no SNC produzindo uma resposta nociceptiva organizada (Mekonnen et al., 2009).

O efeito antiinflamatório do extrato etanólico das folhas de $L$. divaricata, avaliado pelo método do edema de pata induzido por carragenina é mostrado na Figura 4. O aumento de volume da pata dos animais nos tempos de $30 \mathrm{~min}, 1 \mathrm{~h}, 2 \mathrm{~h}$ e $3 \mathrm{~h}$ resultou da agressão causada pelo agente flogístico (carragenina a 1\%) na pata desses animais.

Não houve efeito significativo de nenhuma das quantidades administradas, em relação ao grupo controle, após 30 minutos e duas horas da injeção de carragenina. A dosagem de $160 \mathrm{mg} / \mathrm{kg}$ do extrato inibiu a formação do edema após uma hora da injeção do estimulo inflamatório. Esse resultado foi significativo quando comparado ao grupo tratado com indometacina (Figura 4). Esse resultado sugere que o EEtOH-Ld possui atividade antiinflamatória semelhante à indometacina, capaz de reduzir o edema de pata induzido por carragenina.

Rosa et al. (2014), avaliando as propriedades anti-inflamatórias do extrato bruto de $L$. divaricata, observou uma redução dose-dependente do volume do edema da pata em ratos induzido por carragenina. Este efeito foi evidente 30 minutos após a administração oral do extrato bruto de $L$. divaricata, e mantido durante todo o período de avaliação (Rosa et al., 2014).

Este tipo de teste é utilizado para o desenvolvimento de novos fármacos com potencial antiinflamatório (Morris, 2003; Willoughby, 2003). A carragenina, polissacarídeo sulfatado, é um agente flogístico indutor de um processo inflamatório agudo, que se desenvolve rapidamente devido à ação de vários mediadores pró-inflamatórios, associado à hiperalgesia, e se caracteriza por edema,

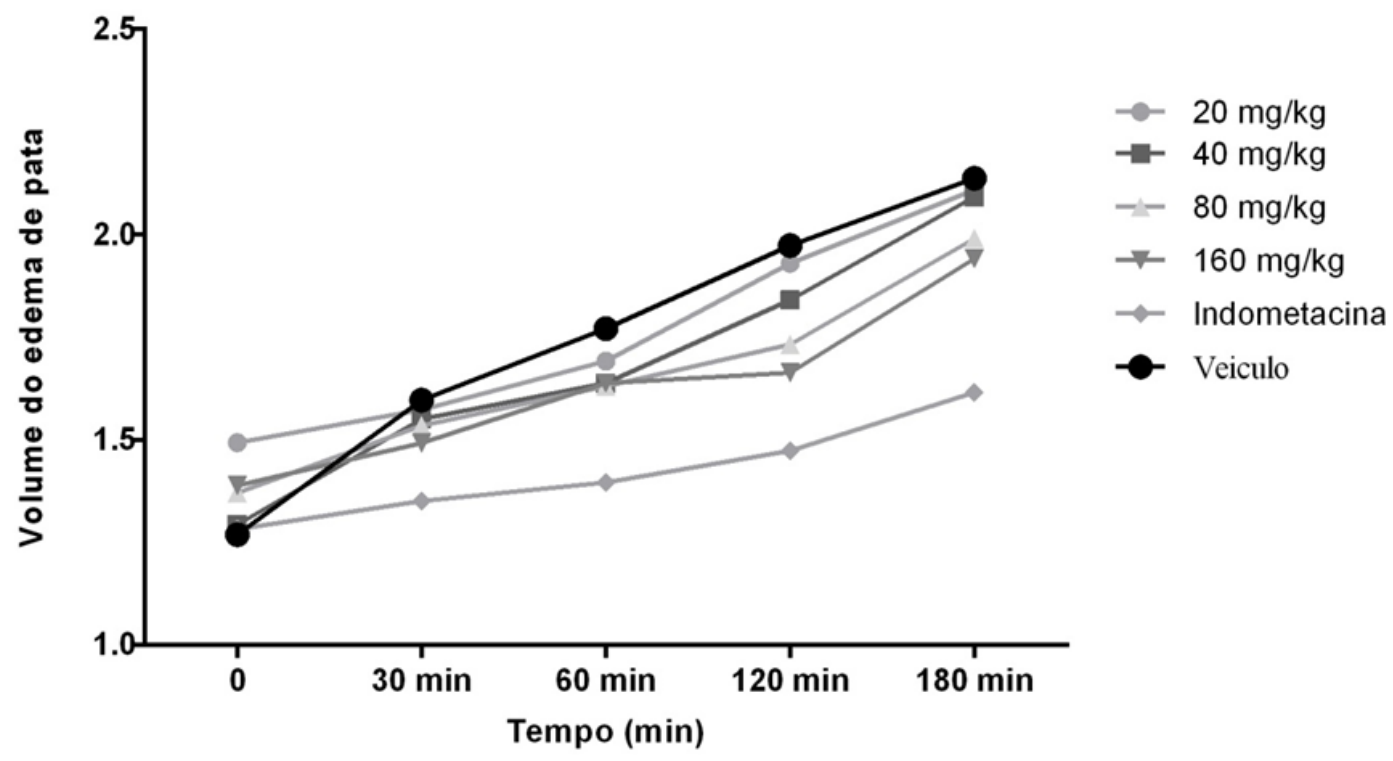

FIGURA 3. Tempo de latência apresentados por camundongos tratados com o extrato etanólico das folhas de Luehea divaricata, em distintos esquemas posológicos no teste de placa quente. 


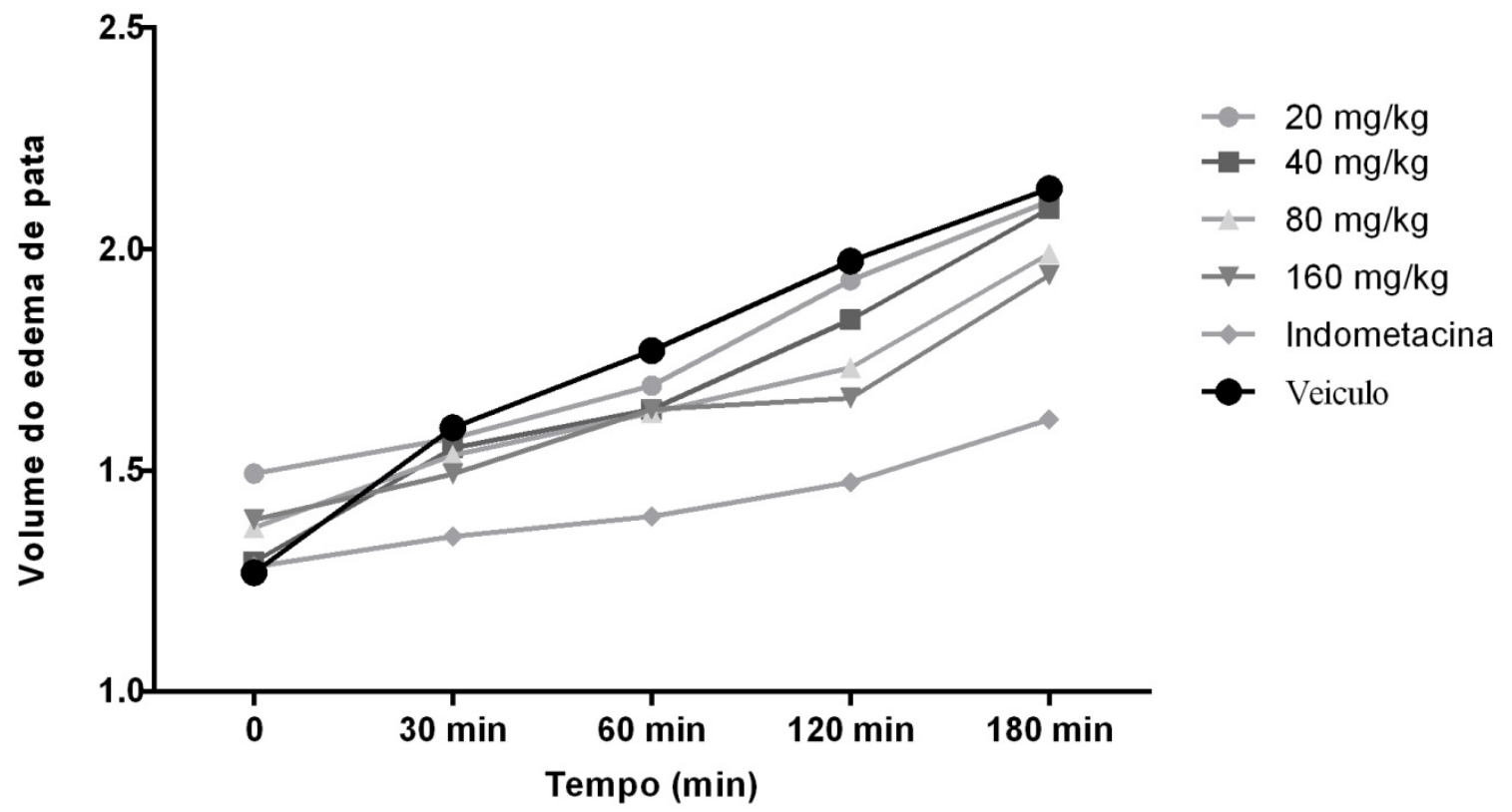

FIGURA 4. Efeito anti-inflamatório do o extrato etanólico de Luehea divaricata sobre o edema de pata induzido por carragenina em ratos, medido com pletismômetro em diferentes pontos temporais.

exacerbada sensibilidade a estímulos térmicos e mecânicos (Morris, 2003; Ferreira et al., 2004).

O edema de pata induzido por carragenina envolve três etapas distintas, de acordo com os mediadores envolvidos. Na etapa inicial, compreendendo os primeiros 90 minutos, ocorre a liberação de histamina e serotonina, responsáveis pela vasodilatação e aumento da permeabilidade vascular no inicio do processo inflamatório. A segunda etapa, que ocorre entre 90 e 150 minutos, é desencadeada por cininas, que tem a capacidade de induzir um aumento na permeabilidade dos vasos sanguíneos e a biossíntese de prostaciclinas e outros autacóides participantes do processo inflamatório. A terceira etapa começa a partir de 150 minutos, quando ocorre aumento da síntese de prostaglandinas no tecido inflamado, com um pico máximo na terceira hora. Nesta fase ocorre uma infiltração maciça de leucócitos polimorfonucleares (Ueno et al., 2000; Carvalho, 2011).

O fato do EEtOH-Ld elevar o limiar de dor induzida pela injeção intraperitoneal de acido acético e injeção intraplantar de formalina, e por inibir a reatividade ao estímulo térmico e o efeito edematogênico induzido pela carragenina, podese inferir que esse extrato é dotado de atividade antinociceptiva, tanto de origem periférica quanto associado a mecanismos centrais de inibição da dor e inflamação, o que remete para a necessidade de aprofundamento dos estudos, sobretudo os direcionados ao(s) mecanismo(s) de ação.

A partir dos resultados deste trabalho conclui-se que o extrato etanólico das folhas de $L$. divaricata, nas dosagens de 20, 40, 80 e $160 \mathrm{mg} /$
$\mathrm{Kg}$, possui atividade antinociceptiva, aumentando o limiar da dor induzida quimicamente por injeções intraperitoneal de acido acético e intraplantar de formalina. Esse extrato também apresenta efeito analgésico central, expresso pela inibição da dor induzida por estímulos térmicos, na dosagem de 160 $\mathrm{mg} / \mathrm{Kg}$, aos 120 minutos de observação. A posologia de $160 \mathrm{mg} / \mathrm{Kg}$ do EEtOH-Ld reduz o edema da pata do rato provocado pela administração de carragenina, em relação ao grupo controle, após uma hora da administração do agente inflamatório.

\section{AGRADECIMENTO}

CAPES - Coordenação de Aperfeiçoamento de Pessoal de Nível Superior e UFPI - Universidade Federal do Piauí

\section{REFERÊNCIAS}

ALICE, C.B. et al. Plantas medicinais de uso popular: Atlas Farmacognóstico. Editora da ULBRA, Canoas, 1995, 205 p.

BAGGIO, A.A.; MEDRADO, M.J.S. Sistemas Agroflorestais e Biodiversidade. In: SEMINÁRIO [SOBRE] SISTEMAS AGROFLORESTAIS E DESENVOLVIMENTO SUSTENTÁVEL, 2003, Campo Grande. Anais... Campo Grande: Embrapa Gado de Corte, 2003. Disponível em: <http://saf.cnpgc.embrapa. br/publicacoes/05.pdf > . Acesso em: 10/09/2012.

BAHAMONDE, S. M. A. et al. Antinociceptive and anti-inflammatory activities of an aqueous extract of Chiliotrichum diffusum. Revista Brasileira de Farmacognosia, v. 23, n. 4, p. 699-705, 2013.

BORTOLUZZI, R.C. et al. Analise química qualitativa e morfo-histológica de Luehea divaricata Mart. In: 
SIMPÓSIO DE PLANTAS MEDICINAIS DO BRASIL, 18, 2002, Cuiabá. Anais... Cuiabá/MG, 2002.

CARVALHO, A.M.R. Estudo da atividade antinociceptiva e antiinflamatória da riparina II (o-metil-n-2hidroxibenzoil tiramina) em modelos experimentais. 2011. 90 f. Dissertação (Mestrado em Farmacologia) Universidade Federal do Ceará, Fortaleza.

CONSELHO FEDERAL DE MEDICINA VETERINÁRIA. Manual de Legislação do Sistema CFMV/CRMVs Resolução $n^{\circ}$ 714, de 20 de junho de 2002. CONSELHO FEDERAL DE MEDICINA VETERINÁRIA. Disponível em: <http://www.cfmv.org.br/portal/legislacao/ resolucoes/resolucao_714.pdf $>$. Acessado em: 20 de set. de 2013.

D'AMOUR, F.E.; SMITH, D.L. A method for determining loss of pain sensation. Journal of Pharmacology and Experimental Therapeutics, v. 72, n. 1, p. 74-79, 1941.

DUTRA, M.G. Plantas medicinais, fitoterápicos e saúde pública: um diagnóstico situacional em Anápolis, Goiás. 2009. 112 p. Dissertação (Mestrado Multidisciplinar em Sociedade, Tecnologia e Meio Ambiente) - Centro Universitário de Anápolis UniEvangélica. Anápolis.

FENG, Y.I., et al. Gabapentin markedly reduces acetic acid-induced visceral nociception. Anesthesiology, v. 98, n. 3, p. 729-733, 2003.

FERREIRA, S.H. A new method for measuring variations of rat paw volume. Journal of Pharmacy and Pharmacology, v. 31, n. 1, p. 648, 1979.

FERREIRA, M.A.D., et al. Analgesic and anti-inflammatory activities of a fraction rich in oncocalyxone $A$ isolated from Auxemma oncocalyx. Phytomedicine, v.11, n. 4, p. 315-322, 2004.

FERREIRA, V. F.; PINTO, A. C. A fitoterapia no mundo atual. Química Nova, v. 33,n. 9, p. 1829, 2010.

GUERRA, M.P.; NODARI, R.O. Biodiversidade e matériasprimas farmacêuticas. In: SIMÕES, C.M.O., et al. Farmacognosia: da planta ao medicamento. 6.ed. Porto Alegre/Florianópolis: Editora da Universidade UFRGS/ Editora da UFSC, 2010, p.13-26.

HESS, S. Atividade antinociceptiva do ácido mirsinóico B. 2006. 107 f. Dissertação (Mestrado em Ciencias Farmaceuticas), Universidade do Vale de Itajaí, Santa Catarina.

HUNSKAAR, S.; HOLE, K. The formalin test in mice: dissociation between inflammatory and non-inflammatory pain. Pain, v. 30, n. 1, p. 103-14, 1987.

IKEDA, K. et al. Infection of the inguinal region treated by musculocutaneous flaps. Journal of Orthopaedic Surgery, v. 9, n. 1, p. 51-56, 2001

LORENZI, H. Árvores brasileiras: manual de identificação e cultivo de plantas arbóreas nativas do Brasil. $2^{\circ}$ ed. Nova Odessa: Plantarum. 1992, 384 p.

MAMET, J., et al. How nerve growth factor drives physiological and inflammatory expressions of acidsensing ion channel 3 in sensory neurons. The Journal of Biological Chemistry, v. 278, p. 48907-48913, 2003.

MEKONNEN, T., et al. Evaluation of the diuretic and analgesic activities of the rhizomes of Rumex abyssinicus Jacq in mice. Journal of Ethnopharmacology, v. 127, n. 2, p. 433-439, 2009.

MORRIS, C. J. Carrageenan-indiced paw edema in the rat and mouse. Methods in molecular biology, v. 225, p. 115-121, 2003.

MULLER, J.B. Avaliação das atividades antimicrobiana, antioxidante e antinociceptiva das folhas da Luehea divaricata Martius. 2006. 99 p. Dissertação (Mestrado em Ciências Farmacêuticas). Universidade Federal de Santa Maria, Rio Grande do Sul.

MUNGUIA, Q. F. B. Mecanismos opioides que participan a nível supraespinal el la potenciacón del efecto antinociceptivo de la combinación tramadol + cafeína em el modelo de la formalina. 2007. 79 p. Dissertação (Mestrado) - Universitad de Colima, Facultad de Medicina, Colima, 2007.

NEWMAN, D.J.; CRAGG, G.M. Natural products as sources of new drugs over the last 25 years. Journal of Natural Products, v. 70, n. 3, p. 461-77, 2007.

OLIVEIRA, R.B., et al Avaliação das atividades antiinflamatoria e analgésica de extrato de Synadenium umbellatum. Revista Eletronica de Farmacia, v. 2, n. 2, p. 137-139, 2005.

PADILHA, M. M. et al. Antinociceptive effect of Morus nigra leaves in mice. Journal of Medicinal Food. v. 12, n. 6 , p. 1381-1385, 2009.

PARVEEN, Z. et al. Antiinflammatory and analgesic activities of Thesium chinense Turcz extracts and its major flavonoids, kaampferol and kaempferol-3-Oglucoside. Yakugaku Zasshi, v. 127, n. 8, p. 1275-1279, 2007.

QUEIROZ, A. C. et al. The antinociceptive and antiinflammatory activities of Piptadenia stipulacea Benth. (Fabaceae). Journal of Ethnopharmacology, v. 128, n. 2, p. 377-83, 2010.

RADU, B. M. et al. Neurovascular unit in chronic pain. Mediators inflammatory. v. 2013, n. 648268, p. 1-18, 2013.

ROSA, R. L. et al. Anti-inflammatory, analgesic, and immunostimulatory effects of Luehea divaricata Mart. \& Zucc. (Malvaceae) bark. Brazilian Journal of Pharmaceutical Sciences, v. 50, n. 3, p. 599-610, 2014.

SANTOS, M.P., et al. Cannabis sativa e Salvia divinorum - uso irresponsável de plantas medicinais com atividade psicoativas. Revista de Trabalhos Acadêmicos, n 2, p. 1-7, 2011.

SILVA, J. C. et al. Modelos experimentais para avaliação da atividade antinociceptiva de produtos naturais: uma revisão. Revista Brasileira de Farmacia, v. 94, n. 1, p. 18-23, 2013.

STEAGALL, P. V. et al. Evaluation of the adverse effects of subcutaneous carprofen over six days in healthy cats. Research in Veterinary Science, v. 86, n. 1, p. 115-20, 2009.

SULAIMAN, M.R. et al. Evaluation of the antinociceptive activity of Ficus deltoidea aqueous extract. Fitoterapia, v. 79, n. 7-8, p. 557-561, 2008.

TANAKA, J.C.A. et al. Constituintes químicos de Luehea divaricata MART. (Tiliaceae). Química Nova, vol. 28, n. 5, p. 834-837, 2005.

TJOLSEN, A. et al.The formalin test: an evaluation of the method. Pain, v. 51, n. 1, p. 5-17, 1992.

UENO, A. et al. Intrinsic prostacyclin contributes to exudation induced by bradykinin or carrageenin: a study on the paw edema induced in ip-receptor-deficient mice. Life Science, v. 66, n. 12, p.155-160, 2000.

VERRI JR, W. A. J. et al. Hypernociceptive role of 
cytokines and chemokines: Targets for analgesicdrug development? Pharmacology \& Therapeutics., v. 112, n. 1, p.116-138, 2006.

VERMA, P. R. et al. Antinociceptive activity of alcoholic extract of Hemidesmus indicus $\mathrm{R}$. Br. in mice. Journal of Ethnopharmacology, v. 102, n. 2, p. 298-301, 2005.

WILLOUGHBY, D.A. In vivo models of inflammation. Methods in Molecular Biology, v. 225, p. 109-113, 2003. 